\title{
The emission of oxygen green line and density of $O$ atom determined by using ISUAL and SABER measurements
}

\author{
H. Gao ${ }^{1,2}$, J.-B. Nee ${ }^{2}$, and J. Xu ${ }^{1}$ \\ ${ }^{1}$ State Key Laboratory of Space Weather, CSSAR, Chinese Academy of Sciences, Beijing, China \\ ${ }^{2}$ Department of Physics, National Central University, Jhongli, Taiwan, China
}

Correspondence to: J.-B. Nee (jbnee@ phy.ncu.edu.tw)

Received: 5 November 2011 - Revised: 28 March 2012 - Accepted: 31 March 2012 - Published: 19 April 2012

\begin{abstract}
Emissions of the $557.7 \mathrm{~nm}$ green line airglow observed by the ISUAL (Imager of Sprites and Upper Atmospheric Lightning) instrument on board the FORMOSAT-2 satellite in May and November 2008 are studied here to derive the density distributions of the atomic oxygen by using atmospheric parameters from MSISE-00 model and TIMED (Thermosphere Ionosphere Mesosphere Energetics and Dynamics)/SABER (Sounding of the Atmosphere using Broadband Emission Radiometry) measurements. The May observations were made in 10 days from a fixed orbit of longitude $\left(100^{\circ} \mathrm{E}\right)$ with the results showing emission rate and $\mathrm{O}$ atom density both peaked at heights of about $90 \mathrm{~km}$ over $10^{\circ}$ to $20^{\circ}$ latitudes in the Northern Hemisphere (NH). In the Southern Hemisphere $(\mathrm{SH})$, the emission rate and density of $\mathrm{O}$ atom are both low compared with those in NH. In November, the observations were made as the satellite traveled over all 14 orbits around the earth, covering all longitudes and latitudes of $25^{\circ} \mathrm{S}-45^{\circ} \mathrm{N}$. Strong peaks of emission rates and $\mathrm{O}$ atoms are found at heights of about $95 \mathrm{~km}$ in the mid-latitudes in both hemispheres. In the equator, the airglow layer has a weaker emission rate but with higher altitude compared with those of mid-latitudes. In the lower and upper mesosphere at heights below $85 \mathrm{~km}$ and above $105 \mathrm{~km}$, there are more $\mathrm{O}$ atoms in the equatorial regions than in the mid-latitudes. And there is a good correlation between the $\mathrm{O}$ atom and the temperature structure. A comparison with $\mathrm{O}$ atom distribution derived from $\mathrm{OH}$ airglow observed by TIMED/SABER at about the same time shows similar results.
\end{abstract}

Keywords. Atmospheric composition and structure (Airglow and aurora; Middle atmosphere - composition and chemistry; Pressure, density, and temperature)

\section{Introduction}

The green line emission at the wavelength $557.7 \mathrm{~nm}$ (hereinafter referred to as $558 \mathrm{~nm})$ arising from the $\mathrm{O}\left({ }^{1} \mathrm{~S}-{ }^{1} \mathrm{D}\right)$ transition is one of the prominent nightglow features in the mesosphere. The production of the excited oxygen atom $\mathrm{O}\left({ }^{1} \mathrm{~S}\right)$ of an energy $4.2 \mathrm{eV}$ was first proposed by Chapman in terms of a three body recombination of $\mathrm{O}$ atoms (Bates, 1988). However, a two-step mechanism involving an excited state of $\mathrm{O}_{2}$ was proposed later by Barth (1961). The Barth Mechanism involves the following steps:

$\mathrm{O}+\mathrm{O}+\mathrm{M} \rightarrow \mathrm{O}_{2}^{*}+\mathrm{M}$

$\mathrm{O}+\mathrm{O}_{2}^{*} \rightarrow \mathrm{O}\left({ }^{1} \mathrm{~S}\right)+\mathrm{O}_{2}$.

Studies of the green line and $\mathrm{O}$ atoms by various measurements have generally favored the Barth mechanism. Previous ground based and rocket measurements have provided useful information about the green line airglow, they are limited in spatial and time domains. The latest development of space instruments such as WINDII (Wind Imaging Interferometer) and SABER have provided extended information about the global and temporal variations of the airglow. For example, Zhang and Shepherd (1999) have shown green line had a midnight enhancement and peaked in mid latitudes based on WINDII observations. In the same study, they have found the $\mathrm{OH}$ Meinel band airglow peaked in the equator. In fact, $\mathrm{OH}$ airglow is also related to the chemistry of $\mathrm{O}$ atom through ozone by the chemical reaction

$\mathrm{H}+\mathrm{O}_{3} \rightarrow \mathrm{OH}^{*}+\mathrm{O}_{2}$

with $\mathrm{O}_{3}$ produced from $\mathrm{O}$ atom by the three body recombination process:

$\mathrm{O}+\mathrm{O}_{2}+\mathrm{M} \rightarrow \mathrm{O}_{3}+\mathrm{M}$. 
Therefore, the measurements of $\mathrm{OH}$ airglow can also provide information about abundance of $\mathrm{O}$ atom. The difference in the latitudinal distributions of the $\mathrm{O}\left({ }^{1} \mathrm{~S}\right)$ and $\mathrm{OH}$ airglow reveals dynamic features governing their global distributions. A study of $\mathrm{O}$ atom from $\mathrm{OH}$ airglow observed by TIMED/SABER instruments is also studied in this paper to compare with results from green line airglow.

McDade et al. (1986) has discussed the mechanism for the production of the green line based on Reactions (R1) and (R2) and derived an expression of the emission rate with the following equation

$$
\begin{aligned}
V_{558 \mathrm{~nm}} & =A_{558 \mathrm{~nm}}\left[\mathrm{O}\left({ }^{1} \mathrm{~S}\right)\right] \\
& =\frac{A_{558 \mathrm{~nm}} \kappa_{1}[\mathrm{O}]^{3}[\mathrm{M}]}{\left\{\left(A\left({ }^{1} \mathrm{~S}\right)+\kappa_{5}\left[\mathrm{O}_{2}\right]\right)\left(C^{\prime}(0)+C^{\prime}(1)[\mathrm{O}]+C^{\prime}(2)\left[\mathrm{O}_{2}\right]\right)\right\}}
\end{aligned}
$$

where [] means number density, $V_{558 \mathrm{~nm}}$ is the emission rate in photons $\mathrm{cm}^{-3} \mathrm{~s}^{-1},[\mathrm{M}]$ is the density of air including both $\mathrm{O}_{2}$ and $\mathrm{N}_{2}$. The rate constant with the three body recombination of $\mathrm{O}$ atoms is $\kappa_{1}=4.7 \times 10^{-33}(300 / T)^{2}$, and the quenching rate of $\mathrm{O}\left({ }^{1} \mathrm{~S}\right)$ by $\mathrm{O}_{2}$ is $\kappa_{5}=2.32 \times$ $10^{-12} \exp \left(\left(-812-1.82 \times 10^{-3} T^{2}\right) / T\right)$ (Capetanakis et al., 1993). In our study, the Einstein coefficients $A_{558 \mathrm{~nm}}$ and $A\left({ }^{1} \mathrm{~S}\right)$ are set as $1.26 \mathrm{~s}^{-1}$ and $1.34 \mathrm{~s}^{-1}$, respectively, which were given by Martin et al. (1999) and used in the study of Nakayama et al. (2006). Constants $C^{\prime(0)}, C^{\prime(1)}$ and $C^{\prime(2)}$ are given in McDade (1986).

From Eq. (1), we find $V_{558 \mathrm{~nm}}$ is proportional to $\mathrm{O}$ atom to a cubic power: $[\mathrm{O}]^{3}$. The rates $k_{1}$ and $k_{5}$ are temperature dependent such that the net emission rate is inversely related to the temperature while $\mathrm{O}$ atom is positively related to the temperature of the atmosphere. By measuring the emission rate at $558 \mathrm{~nm}$, we should be able to derive the density of $\mathrm{O}$ atom with knowledge of the atmospheric temperature and density.

As we have discussed, the $\mathrm{O}$ atom can be studied by emissions of $\mathrm{OH}$ and $\mathrm{O}\left({ }^{1} \mathrm{~S}\right)$. In the past, Russell et al. $(2003,2004)$ have investigated the $\mathrm{O}$ atom distribution based on the green line data from WINDII measurements. Smith et al. (2010) have extensively studied the characteristic height of $\mathrm{O}$ atom over a region of $80-95 \mathrm{~km}$ by using the $\mathrm{OH}$ airglow measured by SABER instrument.

In this paper, we will study the green line and $\mathrm{O}$ atom distributions based on measurements made by the ISUAL instrument on board the FORMOSAT-2 satellite. In the next section, we will discuss the ISUAL instrument and measurements of the green line. In the third section, results of OI558 emission rate and distributions of $\mathrm{O}$ atoms are presented. Results of $\mathrm{O}$ atoms by using different atmospheric parameters and the derivation by using SABER $\mathrm{OH}$ airglow are discussed. Finally, a summary is given in the last section.

\section{Instrument description and data processing}

The ISUAL instrument on board the FORMOSAT-2 satellite was launched in May 2004 to a sun-synchronous orbit of $890 \mathrm{~km}$ with an inclination angle of $98.9^{\circ}$. The satellite has 14 orbits a day circling around the earth and can observe the same region of the atmosphere at a fixed latitude and longitude at the same local time. This type of observation provides a unique opportunity to study the upper atmosphere in detail compared with other non-sun-synchronous satellites which require months to return to the same local time at the same place.

The ISUAL instrument includes a CCD camera which looks through one of six interference filters to observe the atmospheric emissions in limb view (Nee et al., 2010). In this research, Filter \#4 at $558 \mathrm{~nm}$ (FWHM $6 \mathrm{~nm}$ ) is used to capture images of the green line airglow layer. The CCD takes 20 to 41 pictures of the atmosphere as the satellite travels along a specific orbit by looking out a distant window of $3300 \mathrm{~km}$ away. Each CCD picture has 524 (horizontal) $\times$ 128 (vertical) pixels corresponding to a window of $1200 \mathrm{~km}$ (width) $\times 270 \mathrm{~km}$ (height) of the upper atmosphere. A spatial resolution of about $2.14 \mathrm{~km}$ per pixel has been determined from the calibration.

Over the period of 7-16 May 2008, the green line was observed along the \#10 orbit every night at midnight (local time). Forty one pictures were taken as the satellite traveled along this orbit. As an example, Fig. 1a gives a combined image of all 41 pictures to show a single layer of $\mathrm{O}\left({ }^{1} \mathrm{~S}\right)$ airglow observed on 10 May 2008. The observations started from the $\mathrm{SH}$ and ended in $\mathrm{NH}$, covering latitudes of $\sim 11^{\circ} \mathrm{S}-20^{\circ} \mathrm{N}$. The orbit 10 covers longitudes of about $98^{\circ} \mathrm{E}-107^{\circ} \mathrm{E}$ (briefly designated as $100^{\circ} \mathrm{E}$ in this paper). For the second green line observations for 1-2 November 2008, images have been taken along every orbit with orbits on 1 November from \#9 to 14 and on 2 November from \#1 to 8 and also \#10. Therefore, these two day observations in November have covered all regions around the earth. The orbits which the satellite traveled to observe $558 \mathrm{~nm}$ airglow in this period are shown in Fig. 1b where one point on a track represents that one picture was recorded there. There are 21 pictures taken along every orbit (except the \#14 orbit on Nov.1 and the \#7 orbit on 2 November in which 20 pictures were taken because of orbit connectivity. In addition, on 2 November, the \#10 orbit recorded 41 pictures).

By using an "onion-peel" process, the green line volume emission rate profiles can be retrieved from the images as described in Nee et al. (2010). Although there are 512 column pixels in one picture, we just use the 10 central column pixels to produce a profile of the emission rate. These emission rates are then used to calculate the $\mathrm{O}$ atom distributions by using Eq. (1) described in the first section.

The SABER instrument on board the TIMED satellite was launched in December 2001 to an altitude of $625 \mathrm{~km}$ with an inclination angle $74.1^{\circ}$. The satellite travels around the earth 

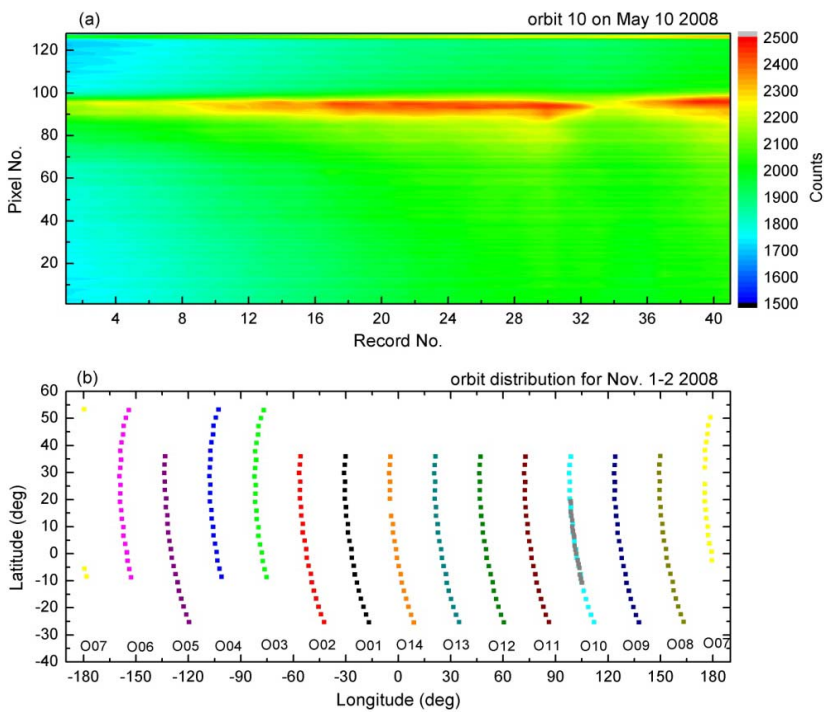

Fig. 1. (a) An image of a layer of $\mathrm{O}\left({ }^{1} \mathrm{~S}\right)$ airglow measured on 10 May 2008. (b) The latitudes and longitudes of ISUAL orbits. For 12 November 2008, one point in the figure represents one picture of the OI558 $\mathrm{nm}$ airglow emission was taken there.

by about 15 orbits and takes about 60 days to cover the whole earth in every $24 \mathrm{~h}$ local time. The SABER instrument is a 10 channel infrared radiometer designed to measure the radiation, energy and structures of the MLT region (mesosphere and lower thermosphere). SABER observations cover from the winter hemisphere $53^{\circ}$ to the summer hemisphere $83^{\circ}$. For every $58 \mathrm{~s}$, SABER scans from 0 to $180 \mathrm{~km}$ to take atmospheric parameters including temperature, density, ozone density and $\mathrm{OH}$ airglow at the emission wavelengths $1.6 \mu \mathrm{m}$ and $2.0 \mu \mathrm{m}$ (see Russell et al., 1999). In this paper, we use the SABER $2.0 \mu \mathrm{m} \mathrm{OH}$ emission and ozone to derive the $\mathrm{O}$ atom by using the method introduced by Smith et al. (2010).

\section{Results}

\section{$3.1558 \mathrm{~nm}$ emission rate}

As an example, Fig. 2 shows the scattered diagrams of the height distributions of the emission rates derived from all 41 images measured on 10 May. Each image can derive a height profile separated by about $0.7^{\circ}$ latitudes from the neighboring images. The black line in Fig. 2 is the average profile of all 41 data. From this figure we can see all data can fit a Gaussian distribution over a height range of $80-110 \mathrm{~km}$ with an average peak height of $92 \mathrm{~km}$. As shown in Fig. 2, the peak height is quite stable for all data despite that the emission intensity can vary by about a factor of two. Such stable height distribution was not observed in $\mathrm{OH}$ airglow (Nee et al., 2010).

The peak height of $\mathrm{O}\left({ }^{1} \mathrm{~S}\right)$ airglow has been reported by many groups using different instruments (Zhang and Shep-

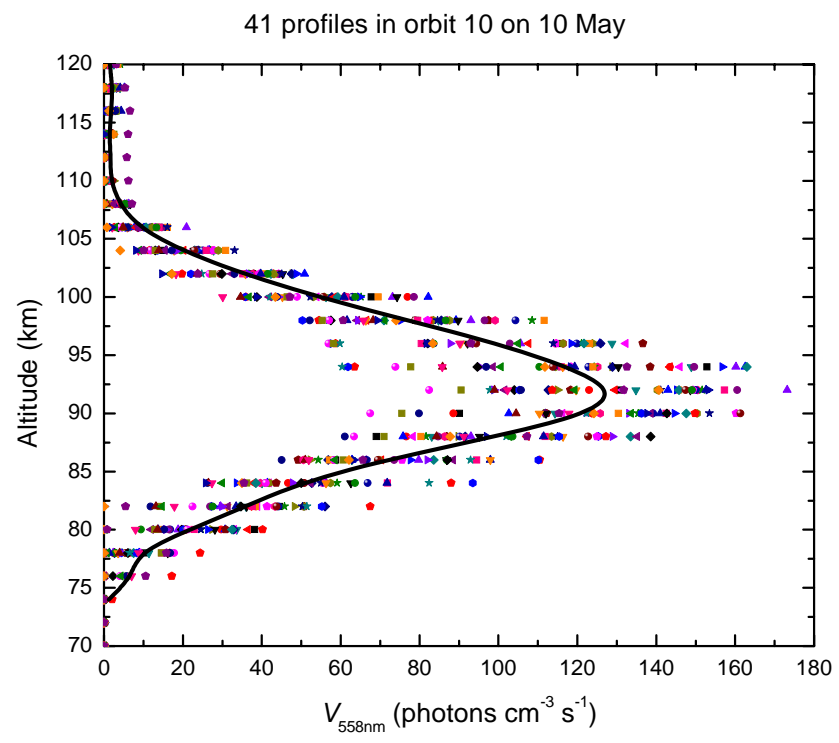

Fig. 2. Forty one scattered profiles of OI558 $\mathrm{nm}$ volume emission rate retrieved from images taken from orbit 10 on 10 May 2008. The 41 data are marked by different colors and symbols with the average profile in black solid line.

herd, 1999; Liu et al., 2008a; Yee et al., 1997; Skinner et al., 1998) and rocket measurements (Melo et al., 1996). The average peak height seems to be about $96 \mathrm{~km}$. Our May observation shows a lower peak height of about $92 \mathrm{~km}$. The difference may be related to the variations of airglow with the time, season and dynamics, as discussed extensively in Liu et al. (2008a) by using WINDII measurement. Long term studies show $\mathrm{O}\left({ }^{1} \mathrm{~S}\right)$ can vary between $84-104 \mathrm{~km}$ depending on the season and time (Liu et al., 2008a). The HRDI (High Resolution Doppler Imager) instrument also shows seasonal and local time variations of green line airglow (Skinner et al., 1998).

A contour diagram for green line in terms of height versus latitude can be made by averaging the emission rate in grids of 5 degree latitudes as shown in Fig. 3a and b for May and November data. For May data the measurements were made over a fixed longitude of about $100^{\circ} \mathrm{E}$ and latitudes of $10^{\circ} \mathrm{S}-20^{\circ} \mathrm{N}$. We find the peak height is about $92 \mathrm{~km}$ and the peak emission in the $\mathrm{NH}$ is higher than that in the SH. For November data, the measurements were made over the latitudes of $25^{\circ} \mathrm{S}-45^{\circ} \mathrm{N}$ but over all longitudes. The results of averaging all longitudes gives a global distribution, showing green line emission at the equator is high in altitude but weak in intensity compared with those of mid-latitudes which have lower peak heights but stronger emission intensity. The two mid-latitude maxima are at about $95 \mathrm{~km}$ at $25^{\circ} \mathrm{S}$ and $93 \mathrm{~km}$ at $30^{\circ} \mathrm{N}$ with emission rates of 180 photons $\mathrm{cm}^{-3} \mathrm{~s}^{-1}$ and 240 photons $\mathrm{cm}^{-3} \mathrm{~s}^{-1}$, respectively. Our results are basically consistent with WINDII/UARS data of Zhang and Shepherd (1999) who have shown OI558 nm emission rates are low near equator but high in the mid-latitudes for March 1992, 

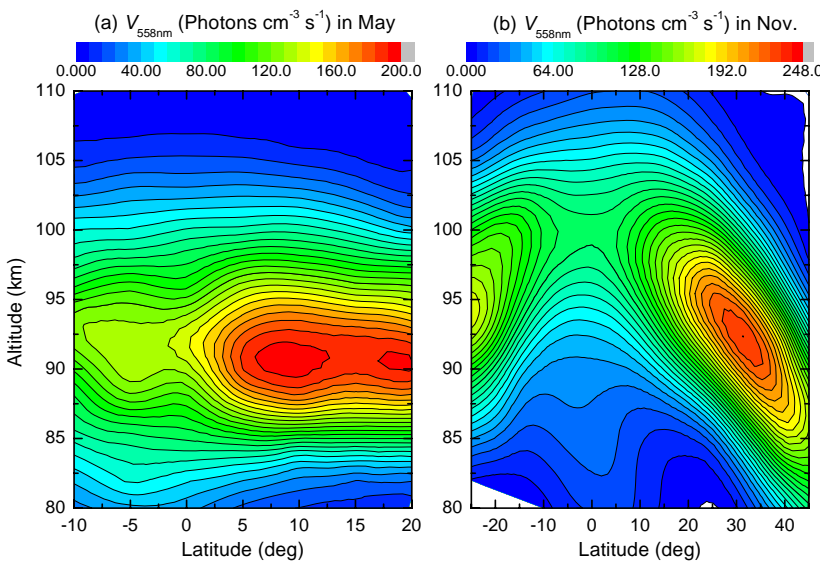

Fig. 3. The height-latitudinal distributions of green line emission rates observed by ISUAL in (a) May 2008 along orbit 10 (longitude $\sim 100^{\circ} \mathrm{E}$ ) and (b) November 2008 averaging over all longitudes.

December 1992, and February 1993 at midnight conditions. We also find the magnitudes of the emission rates of ISUAL and WINDII data are close (Shepherd et al., 1999; Wang et al., 2002; Liu et al., 2008b).

We notice that the global measurement reveals a symmetric distribution with respect to the equator with the $\mathrm{NH}$ and SH peaks, appearing as mirror images of each other as shown in Fig. 3b. The symmetric distribution is also found in WINDII observation as shown in Zhang and Shepherd (1999).

\subsection{Derivation of $\mathrm{O}$ atom density based on MSIS model}

As discussed above, we can use the $558 \mathrm{~nm}$ emission rate to derive the density distribution of $\mathrm{O}$ atoms by using Eq. (1) with the knowledge of background atmospheric temperature and density. Russell et al. (2003, 2004) used the MSIS model to calculate $\mathrm{O}$ atom based on WINDII $558 \mathrm{~nm}$ data. We also used MSISE-00 model to derive $\mathrm{O}$ atom by using ISUAL OI $558 \mathrm{~nm}$ emission rate. We have selected the model calculations by using the same time and geological coordinates corresponding to the observations. Figure 4 a shows 41 scattered diagrams of height distributions of $\mathrm{O}$ atom measured along the longitude $100^{\circ} \mathrm{E}$ corresponding to the emissions shown in Fig. 2. The average profile is shown as the solid black line. From Fig. 4a we can see $\mathrm{O}$ atom on 10 May has a peak at about $92 \mathrm{~km}$ and a minimum at about $112 \mathrm{~km}$. O atom increases with altitude above $112 \mathrm{~km}$, reaching a secondary peak above $120 \mathrm{~km}$. However, we must be reminded there are also more errors at heights below $80 \mathrm{~km}$ and above $110 \mathrm{~km}$ where emission rates are low and standard deviations are high.

Based on results shown in Fig. 4a, the $\mathrm{O}$ atom distribution can be fitted with a Chapman profile as described in Eq. (2) below. This is the way Reed and Chandra (1975) and Melo
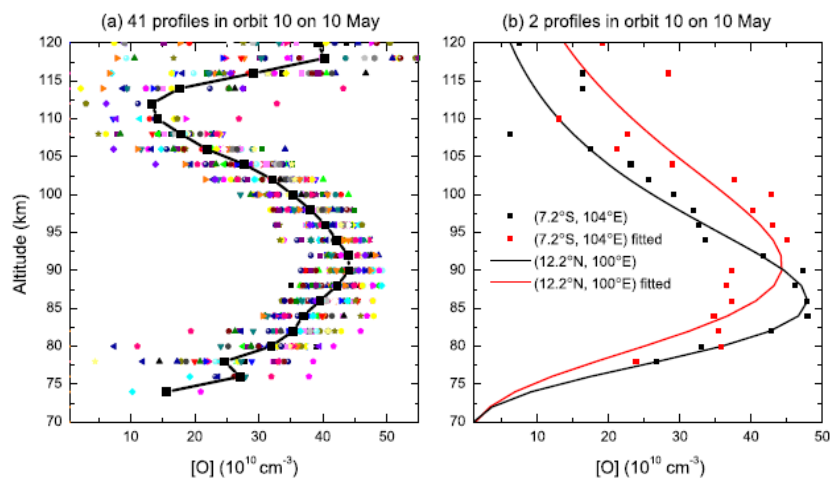

Fig. 4. (a) Height distributions of $\mathrm{O}$ atom derived from forty-one $558 \mathrm{~nm}$ emission rates observed along orbit 10 on 10 May 2008 (in different symbols and colors). The solid black line represents the average profile. (b) Two profiles of specific latitudes and longitudes $\left(7.2^{\circ} \mathrm{S}, 104^{\circ} \mathrm{E}\right)$ and $\left(12.2^{\circ} \mathrm{N}, 100^{\circ} \mathrm{E}\right)$ (doted lines), and their simulated results (solid lines) by using Eq. (2).

et al. (2001) reported their distributions for the mesospheric $\mathrm{O}$ atoms:

$[\mathrm{O}]_{z}=[\mathrm{O}]_{\max } \exp \left\{0.5\left[1-\left(z-h_{\max }\right) / w\right]-\exp \left[-\left(z-h_{\max }\right) / w\right]\right\}$.

In Eq. (2), $[\mathrm{O}]_{z}$ is the atomic oxygen density at an altitude $z$; $[\mathrm{O}]_{\max }$ and $h_{\max }$ are the peak density and height of the atomic oxygen, respectively, and $w$ is the width of profile.

By using Eq. (2), we have simulated the $\mathrm{O}$ atom distribution in $70-120 \mathrm{~km}$ by a least-square fit. In Fig. $4 \mathrm{~b}$, the dots are the height distributions of two observations at $\left(7.2^{\circ} \mathrm{S}\right.$, $\left.104^{\circ} \mathrm{E}\right)$ and $\left(12.2^{\circ} \mathrm{N}, 100^{\circ} \mathrm{E}\right)$ and solid lines for the fitting results. In this figure, we find the height distributions of $\mathrm{O}$ atoms in the $\mathrm{NH}$ and $\mathrm{SH}$ are different, which should result from slightly un-symmetric distribution of airglow intensities in $\mathrm{NH}$ and $\mathrm{SH}$, as can be seen in Fig. 3a.

It is known that MSISE-00 as an empirical model provides a good representation of the atmosphere in the region of middle to lower mesosphere but is not very accurate in the mesopause region (Xu et al., 2006). Recently by comparing the TIMED data with MSISE-00, Xu et al. (2006) have reported the deviations of MSISE-00 model. They also found inconsistency for cases of temperature inversions and some small scale deviations at different seasons.

\subsection{Mesospheric temperatures based on SABER observations}

We have employed TIMED/SABER temperature and density data as an alternative to the MSIS model for the calculations of $\mathrm{O}$ atom. One of the problems of using SABER measurements with ISUAL is related to their different orbits and observation strategies. It is rare that both satellites will be located at the same region to observe the same atmosphere 

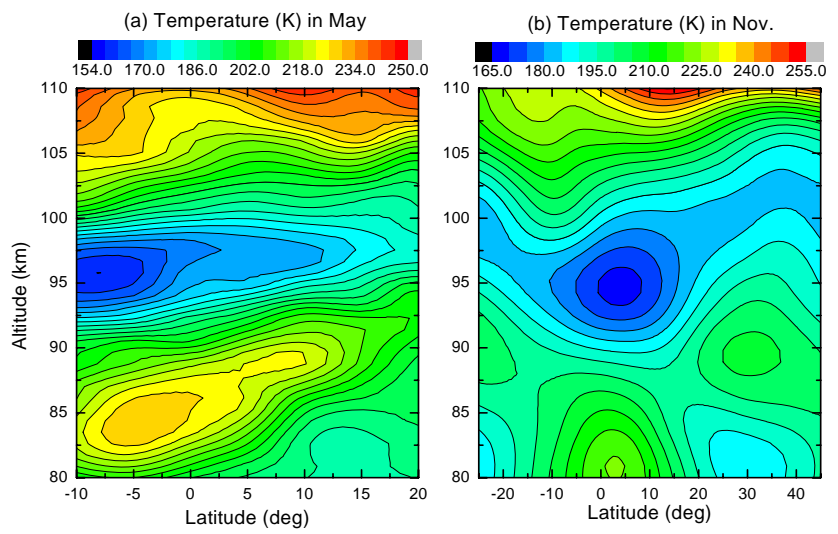

Fig. 5. SABER temperatures correspond to the same orbital conditions for (a) May and (b) November airglow observations.

at the same time. Fortunately, SABER observations were made around midnight in both periods of 7-16 May and 12 November 2008. We have therefore selected SABER observations for heights of $80-110 \mathrm{~km}$ during 7-16 May 2008 with the longitudes between $90^{\circ} \mathrm{E}$ and $110^{\circ} \mathrm{E}$ and during 12 November 2008 in all longitudes in the time interval of $-02: 00 \mathrm{LT}$ to 02:00 LT local time to construct bins of $5 \mathrm{de}-$ gree latitudes. We then used ISUAL OI $558 \mathrm{~nm}$ emission rate to calculate $\mathrm{O}$ atom density within these bins.

We will first look at the SABER temperature data since it is an important parameter in the calculations. Figure 5 shows contour diagrams of SABER temperatures for both May and November in 2008. We find from Fig. 5a the mesopause in May is located at about $97 \mathrm{~km}$ with a low temperature of about $160 \mathrm{~K}$. Below the mesopause, there is a warm layer with a local temperature maximum of about $220 \mathrm{~K}$ at about $83 \mathrm{~km}$ at $10^{\circ} \mathrm{S}$. The height of this warm layer increases to $92 \mathrm{~km}$ at $20^{\circ} \mathrm{N}$. Higher temperatures also appear above $105 \mathrm{~km}$.

For November, the temperature structure shows a complex pattern in terms of multiple highs and lows. The mesopause height is at $95 \mathrm{~km}$ over the equatorial region and increases to about $100 \mathrm{~km}$ at mid-latitudes in the $\mathrm{SH}$ and $\mathrm{NH}$ as shown in Fig. $5 \mathrm{~b}$. In the lower mesosphere at about $85 \mathrm{~km}$, the temperature in the equatorial region is higher than those in the mid-latitudes. But in the upper mesosphere at heights 100$110 \mathrm{~km}$, there is a warm layer corresponding to the thermosphere. In November, high temperatures in the mesosphere can be found in three regions: $81 \mathrm{~km}$ over the equator, $90 \mathrm{~km}$ at both $25^{\circ} \mathrm{S}$ and $30^{\circ} \mathrm{N}$. The highest temperature appears above the mesosphere at $110 \mathrm{~km}$ at $10^{\circ} \mathrm{N}$.

By comparing Fig. 5b with Fig. 3b, we can see the stronger $558 \mathrm{~nm}$ airglow layer lies near the mesopause. We must be reminded that emission is negatively correlated and $\mathrm{O}$ atom is positively correlated with temperature as given in Eq. (1), so that peak emission and $\mathrm{O}$ atom are correlated with cold and warm regions, respectively.

\subsection{O atom based on SABER observations}

By using SABER temperature and density data in Eq. (1), we have calculated $\mathrm{O}$ atom distributions for May and November with results shown in Fig. 6. Figure 6a indicates a layer of $\mathrm{O}$ atoms exists in May at $85-95 \mathrm{~km}$ with the peak height increasing with latitude even though the emission rate is relatively unchanged in height distribution as shown in Fig. 3a. This difference should be attributed to the temperature distribution as shown in Fig. 5a. The number density of $\mathrm{O}$ atoms in the $\mathrm{NH}$ is more and higher than those in the SH. A maximum of $\mathrm{O}$ atom appears at $10^{\circ} \mathrm{N}$ at $90 \mathrm{~km}$. Besides these trends, there is a low value of $\mathrm{O}$ atom at about $95 \mathrm{~km}$ at $10^{\circ} \mathrm{S}$ in the $\mathrm{SH}$ related to the temperature conditions shown in Fig. 5a.

In November, $\mathrm{O}$ atom shows several maxima and minima in different heights and latitudes. Below $85 \mathrm{~km}$, more $\mathrm{O}$ atoms are found at the equator than other regions. In the mid-latitudes there are two minima found at about $25^{\circ} \mathrm{S} / \mathrm{N}$. In the region of $85-100 \mathrm{~km}$, there is a peak of $\mathrm{O}$ atom at about $93 \mathrm{~km}$ at $30^{\circ} \mathrm{N}$. The corresponding peak in the $\mathrm{SH}$ should lie at $30^{\circ}$ but was partially cut in the diagram. These two mid-latitude peaks form mirror images similar to the emission double shown in Fig. 3b. A major peak of $\mathrm{O}$ atom is located at about $10^{\circ} \mathrm{N}$ at $110 \mathrm{~km}$, and a secondary peak at $10^{\circ} \mathrm{S}$ at $104 \mathrm{~km}$. The last two peaks lying above $100 \mathrm{~km}$ are correlated with the temperature structure in this region as can be seen in Fig. $5 \mathrm{~b}$. The secondary peak at $10^{\circ} \mathrm{S}$ may be a split from the major peak.

In terms of absolute number density, $\mathrm{O}$ atoms in May or November are both in the level of $10^{11} \mathrm{~cm}^{-3}$ which is close to other results reported in the literatures (e.g. Smith et al., 2010; Russell et al., 2003). We also calculated the volume mixing ratio (vmr) of $\mathrm{O}$. The altitude-latitude distribution of the vmr below $100 \mathrm{~km}$ is very similar to the calculations of Smith et al. (2010) who used SABER OH(2.0 $\mu \mathrm{m})$ airglow to derive the $\mathrm{O}$ atom density and mixing ratio. In addition, our results indicate that the $\mathrm{O}$ atom at $10^{\circ} \mathrm{N}(109 \mathrm{~km})$ has a mixing ratio about 0.4 compared with less than 0.3 at all other latitudes and heights.

\subsection{Discussion}

Following Smith et al. $(2008,2010)$ and using the new coefficients given by Xu et al. (2012), we also calculated the $\mathrm{O}$ atoms in the $80-100 \mathrm{~km}$ height region based on SABER $\mathrm{OH}(2.0 \mu \mathrm{m})$ airglow emission rate and ozone density measured in the period of 7-16 May 2008 in -02:00-02:00 LT and in longitudes $90^{\circ} \mathrm{E}-110^{\circ} \mathrm{E}$. Another calculation has been made for 1-2 November 2008 at -02:00-02:00 LT but over all longitudes. The altitude-latitude distribution of the $\mathrm{O}$ atom retrieved from SABER May data shows $\mathrm{O}$ atoms peaks over the latitudes $10^{\circ} \mathrm{S}-20^{\circ} \mathrm{N}$ and heights $80-100 \mathrm{~km}$ similar to what are displayed in Fig. 6a. There are more O atom in the $\mathrm{NH}$ than the $\mathrm{SH}$ and the peak height increases in general toward mid-latitudes in the NH. SABER data also 

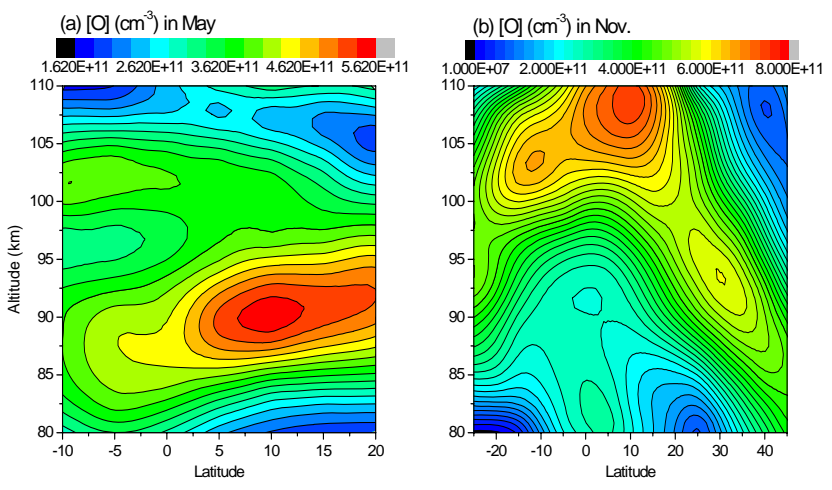

Fig. 6. Atomic oxygen density in latitude-height contour for (a) May and (b) November.

find low $\mathrm{O}$ atoms in the $\mathrm{SH}$ and equator at about $95 \mathrm{~km}$. For SABER November data over the latitudes $25^{\circ} \mathrm{S}-45^{\circ} \mathrm{N}$ and heights above $85 \mathrm{~km}$, peak $\mathrm{O}$ atoms are lying higher but with less density in the equator than those in the mid-latitudes similar to what is shown in Fig. 6b. Below $85 \mathrm{~km}$, O atom has higher density in the equatorial region than that at midlatitudes. SABER results also show $\mathrm{O}$ atom density is in the level of $10^{11} \mathrm{~cm}^{-3}$.

We also analyzed the altitude-latitude distributions of $\mathrm{O}$ atom derived from the green line emission by using the atmospheric density and temperature from MSISE-00 model. The results indicate the distributions in both May and November are generally similar to those derived based on SABER observations as shown in Fig. 6. Meanwhile some small differences exist. For example, calculations made with MSISE-00 model show constant altitudinal and latitudinal variations of $\mathrm{O}$ atom density and there is not a low density region around $95 \mathrm{~km}$ in the SH in May. This can be attributed to that there is not such structure in the distribution of temperature from MSISE-00 model.

It is worth mentioning that two coefficients $C^{\prime(1)}$ and $C^{\prime}(2)$ in Eq. (1) are taken as 211 and 15 in our study. In fact, McDade et al. (1986) got four different sets of values for the two coefficients by fitting the green line emission rate profiles from ETON rocket experiments using Eq. (1). In the fitting, they used four different sets of $[\mathrm{O}]$ which were obtained based on the [O] from CIRA 1972 and MSIS-83 atmospheric models, respectively. In this work, we use the values of $C^{\prime}(1)$ and $C^{\prime}(2)$ obtained based on MSIS-83 model. However, the atmospheric temperature and density from MSISE-00 model and SABER are used, which are different from MSIS-83 model. We will discuss the uncertainty in the derivation of $[\mathrm{O}]$ using new data and model due to the values of $C^{\prime(1)}$ and $C^{\prime}(2)$ from MSIS-83 model.

According to the maximum and minimum of $C^{\prime(1)}$ and $C^{\prime}(2)$ given in Table 3 of McDade et al. (1986), we assume $C^{\prime(1)}$ and $C^{\prime(2)}$ decreasing by $10 \%$ and $30 \%$, which means $C^{\prime(1)}$ and $C^{\prime(2)}$ are set as $0.9 C^{\prime(1)}$ and $0.7 C^{\prime(2)}$, respectively.
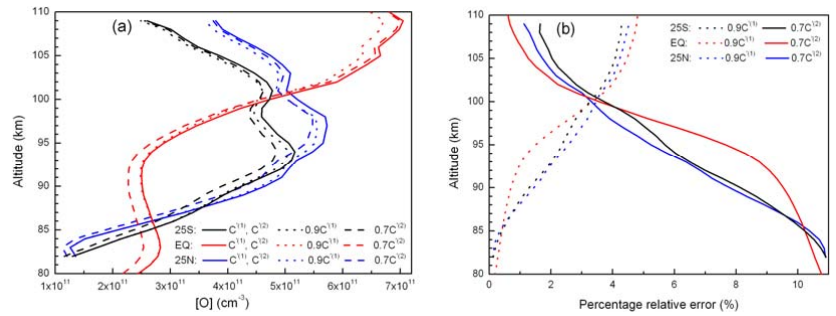

Fig. 7. (a) Altitudinal distributions of $[\mathrm{O}]$ at three latitudes derived by using three sets of values: $C^{\prime(1)}$ and $C^{\prime(2)}, 0.9 C^{\prime(1)}$ and $C^{\prime(2)}$, $C^{\prime}(1)$ and $0.7 C^{\prime(1)}$, and (b) the percentage errors of [O] derived by using the second and third sets of coefficients.

We use the new values to derive the $[\mathrm{O}]$ at three latitudes: $25^{\circ} \mathrm{N} / \mathrm{S}$ and the equator, by using the atmospheric temperature and density from SABER. We also calculate the percentage errors as follows:

$$
\begin{aligned}
100 \% & \times\left|[\mathrm{O}]_{0.9 C^{\prime(1)}, C^{\prime(2)}}-[\mathrm{O}]_{C^{\prime(1)}, C^{\prime(2)}}\right| /[\mathrm{O}]_{C^{\prime(1)}, C^{\prime(2)}}, 100 \% \\
& \times\left|[\mathrm{O}]_{C^{\prime(1)}, 0.7 C^{\prime(2)}}-[\mathrm{O}]_{C^{\prime(1)}, C^{\prime(2)}}\right| /[\mathrm{O}]_{C^{\prime(1)}, C^{\prime(2)}} .
\end{aligned}
$$

The results are shown in Fig. 7a and b. From this figure, we can see that the derived [O] decreases with $C^{\prime(1)}$ or $C^{\prime(2)}$, decreasing at all altitudes and latitudes. And all uncertainties of [O] are less than $11 \%$ as shown in Fig. $7 \mathrm{~b}$.

\section{Summary}

By using the ISUAL instrument on board the sunsynchronous satellite FORMOSAT-2, the images of the OI $558 \mathrm{~nm}$ green line airglow emission was measured on 7-16 May 2008 and 1-2 November 2008. The profiles of OI $558 \mathrm{~nm}$ emission rates are derived from the observation by using an "onion-peel" process. Furthermore, the $\mathrm{O}$ atom density profiles are retrieved from the OI $558 \mathrm{~nm}$ emission rates by using atmospheric temperature and density from SABER and MSISE-00 model, respectively.

The May 2008 observation made at an averaged longitude of $100^{\circ} \mathrm{E}$ shows emission rates peaked at about $92 \mathrm{~km}$ over the latitudes $10^{\circ} \mathrm{S}-20^{\circ} \mathrm{N}$. The retrieved $\mathrm{O}$ atoms have peak heights increasing toward the $\mathrm{NH}$. Both the emission rate and $\mathrm{O}$ density are higher in $\mathrm{NH}$.

For 1-2 November 2008, ISUAL observations were made globally by traveling over all longitudes and a latitude range of $25^{\circ} \mathrm{S}-45^{\circ} \mathrm{N}$. In November, the OI $558 \mathrm{~nm}$ emission rates and $\mathrm{O}$ atoms show double maxima at about $95 \mathrm{~km}$ in the midlatitudes. The double peaks at mid-latitudes are symmetrically distributed with respect to the equator. In the equatorial region, peak $\mathrm{O}$ atom density was found around $10^{\circ} \mathrm{N}$ at $110 \mathrm{~km}$ in the lower thermosphere. In the lower mesosphere around $82 \mathrm{~km}$, there are double minima of $\mathrm{O}$ atoms in the mid-latitudes also symmetrically located. 
We also calculate $\mathrm{O}$ atom by using SABER $\mathrm{OH}$ airglow. The results show similar distribution to that from ISUAL green line observations.

Acknowledgements. We thank the FORMOSAT-2 and TIMED/SABER science teams for providing the data used in this study. GH wishes to thank National Science Council for postdoctor position at NCU. This research is supported through a grant: NSC100-2811-M-008-004. This work is supported by the Chinese Academy of Sciences (KZZD-EW-01-2), the National Science Foundation of China (41004062, 40921063, 40890165) and the National Important Basic Research Project of China (2011CB811405). The project is also supported by the Specialized Research Fund for State Key Laboratories.

Topical Editor C. Jacobi thanks two anonymous referees for their help in evaluating this paper.

\section{References}

Barth, C. A. and Hildebrandt, A. F.: The 5577 A airglow emission mechanism, J. Geophys. Res., 66, 985-986, 1961.

Bates, D. R.: Excitation of $557.7 \mathrm{~nm}$ OI line in nightglow, Planet. Space Sci., 36, 883-889, 1988.

Capetanakis, F. P., Sondermann, F., Höser, S., and Stuhl, F.: Temperature dependence of the quenching of $\mathrm{O}(1 \mathrm{~S})$ by simple inorganic molecules, J. Chem. Phys., 98, 7883-7887, 1993.

Liu, G., Shepherd, G. G., and Roble, R. G.: Seasonal variations of the nighttime $\mathrm{O}(1 \mathrm{~S})$ and $\mathrm{OH}$ airglow emission ratesat mid-tohigh latitudes in the context of the large-scale circulation, J. Geophys. Res., 113, A06302, doi:10.1029/2007JA012854, 2008a.

Liu, G., Shepherd, G. G., and Tepley, C. A.: Variations of the tropical $\mathrm{O}(1 \mathrm{~S})$ nightglow as observed with the Arecibo Observatory photometer and WINDII on UARS, J. Atmos. Sol.-Terr. Phys., 70, 1309-1317, 2008b.

Martin, W. C., Fuhr, J. R., Kelleher, D. E., Musgrove, A., Podobedova, L., Reader, J., Saloman, J. E. B., Sansonetti, C. J., Wiese, W. L., Mohr, P. J., and Owen, K.: NIST Atomic Spectra Database (version 2.0), National Institute of Standards and Technology, Gaithersburg, MD, available at: http://physics.nist.gov/ asd, 1999.

McDade, I. C., Murtagh, D. P., Greer, R. G. H., Dickinson, P. H. G., Witt, G., Stegman, J., Llewellyn, E. J., Thomas, L., and Jenkins, D. B.: ETON 2: Quenching parameters for the proposed precursors of $\mathrm{O} 2(\mathrm{~b} 1 \Sigma \mathrm{g}+)$ and $\mathrm{O}(1 \mathrm{~S})$ in the terrestrial nightglow, Planet. Space Sci., 34, 789-800, 1986.

Melo, S. M. L., Takahashi, H., Clemesha, B. R., Batista, P. P., and Simonich, D. M.: Atomic oxygen concentrations from rocket airglow observations in the equatorial region, J. Atmos. Terr. Phys., 58, 1935-1942, 1996.

Melo, S. M. L., McDade, I. C., and Takahashi, H.: Atomic oxygen density profiles from ground-based nightglow measurements at $23^{\circ}$ S, J. Geophys. Res., 106, 15377-15384, 2001.

Nakayama, T., Takahashi, K., Matsumi, Y., and Fujiwara, H.: Laboratory study of $\mathrm{O}(1 \mathrm{~S})$ formation process in the photolysis of $\mathrm{O}_{3}$ and its atmospheric implications, J. Atmos. Chem., 53, 107-122, 2006.
Nee, J.-B., Tsai, S.-D., Peng, T.-H., Hsu, R.-R., Chen, A. B.-C., Zhang, S., Huang, T.-Y., Rajesh, P. K., Liu, J.-Y., Frey, H. U., and Mende, S. B.: OH Airglow and Equatorial Variations Observed by ISUAL Instrument on Board the FORMOSAT-2 Satellite, Terr. Atmos. Ocean. Sci., 21, 985-995, 2010.

Reed, E. I. and Chandra, S.: The Global Characteristics of Atmospheric Emissions in the Lower Thermosphere and Their Aeronomic Implications, J. Geophys. Res., 80, 3053-3062, 1975.

Russell, J. M., Mlynczak, M. G., Gordley, L. L., Tansock, J., and Esplin, R.: An overview of the SABER experiment and preliminary calibration results, Proc. SPIE Int. Soc. Opt. Eng., 3756, 277-288, 1999.

Russell, J. P. and Lowe, R. P.: Atomic oxygen profiles (80$94 \mathrm{~km}$ ) derived from Wind Imaging Interferometer/Upper Atmospheric Research Satellite measurements of the hydroxyl airglow: 1. Validation of technique, J. Geophys. Res., 108, 4662, doi:10.1029/2003JD003454, 2003.

Russell, J. P., Lowe, R. P., and Ward, W. E.: Atomic oxygen annual and semi-annual variations in the mesopause region for mid and equatorial latitudes, J. Atmos. Sol.-Terr. Phys., 66, 451-461, 2004.

Shepherd, G. G., Zhang, S., and Wang, X.: Variability in MLT dynamics and species concentrations as observed by WINDII, Earth Planets Space, 51, 845-853, 1999.

Skinner, W. R., Yee, J.-H, Hays, P. B., and Burrage, M. D.: Seasonal and local time variations in the $\mathrm{O}(1 \mathrm{~S})$ green line, $\mathrm{O} 2$ atmospheric band, and $\mathrm{OH}$ Meinel band emissions as measured by the High Resolution Doppler Imager, Adv. Space Res., 21, 835-841, 1998.

Smith, A. K., Marsh, D. R., Russell III, J. M., Mlynczak, M. G., Martin-Torres, F. J., and Kyrölä, E.: Satellite observations of high nighttime ozone at the equatorial mesopause, J. Geophys. Res., 113, D17312, doi:10.1029/2008JD010066, 2008.

Smith, A. K., Marsh, D. R., Mlynczak, M. G., and Mast, J. C.: Temporal variations of atomic oxygen in the upper mesosphere from SABER, J. Geophys. Res., 115, D18309, doi:10.1029/2009JD013434, 2010.

Wang, D. Y., Ward, W. E., Solheim, B. H., and Shepherd, G. G.: Longitudinal variations of green line emission rates observed, J. Atmos. Sol.-Terr. Phys., 64, 1273-1286, 2002.

Xu, J., Ji, Q., Wei, Y., and Ma, R.: Comparison between the TIMED observed global temperature distribution and the MRLMSISE-00 empirical atmospheric model, Chin. J. Space Sci., 26, 177-182, 2006 (in Chinese).

Xu, J., Gao, H., Smith, A. K., and Zhu, Y.: Using TIMED/SABER nightglow observations to investigate hydroxyl emission mechanisms in the mesopause region, J. Geophys. Res., 117, D02301, doi:10.1029/2011JD016342, 2012.

Yee, J.-H., Crowley, G., Roble, R. G., Skinner, W. R., Burrage, M. D., and Hays, P. B.: Global simulations and observations of $\mathrm{O}\left({ }^{1} \mathrm{~S}\right), \mathrm{O}_{2}\left({ }^{1} \Sigma\right)$ and $\mathrm{OH}$ mesospheric nightglow emissions, J. Geophys. Res., 102, 19949-19968, doi:10.1029/96JA01833, 1997.

Zhang, S. P. and Shepherd, G. G.: The influence of the diurnal tide on the $\mathrm{O}\left({ }^{1} \mathrm{~S}\right)$ and $\mathrm{OH}$ emission rates observed by WINDII on UARS, Geophys. Res. Lett., 26, 529-532, doi:10.1029/1999GL900033, 1999. 